\title{
BRONCHIAL SPASM DURING GENERAL ANAESTHESIA
}

\author{
Victor Brandus, M.D., Sarah Joffe, M.D., Chardes V. Benort, M.D., \\ AND WIIIIAM I. WOLFF, M.D.*
}

THE GRAVITY OF AN ATTACK of bronchial spasm in an unconscious patient depends on its intensity. If severe, it is a life-threatening condition and the time available for treatment is limited to only a few minutes. In our combined professional experience we have lost two such patients: the first, while passing a nasogastric tube in a young man who had taken an overdose of barbiturate; the second was a middle-aged female having a cholecystectomy under cyclopropane anaesthesia. Two recent cases of severe bronchial spasm, developed during induction of anaesthesia, were successfully treated with local anaesthetic drugs administered intravenously. The pertinent data from their case histories form the basis of this report.

\section{Case Reports}

\section{Case I}

A.N., a 64-year-old white housewife, weight $57 \mathrm{~kg}$, was admitted to the hospital on July 24,1967 , for surgical removal of a tumour of the right breast. The patient had a history of borderline glaucoma (not on medication), of chronic dry cough (not productive), and of heavy smoking which had been given up, in the past, at an unspecified date. There was no history of allergies. Physical examination was not remarkable except for signs consistent with the diagnosis of carcinoma of the breast, with involvement of the axillary lymph nodes. On chest roentgenograms, irregular infiltrative densities were seen in the region of the right mid-lung field, the nature of which it was not possible to diagnose at that time. Laboratory studies and electrocardiogram were within normal limits, and the haemoglobin concentration was $13.8 \mathrm{gm}$ per cent.

On the morning of surgery the patient was calm, her arterial blood pressure was $100 / 70 \mathrm{~mm} \mathrm{Hg}$, the pulse rate was 80 and the respiratory rate 15 per minute, and the lungs were clear on auscultation.

Pre-anaesthetic medication consisted of secobarbital (Seconal sodium®) $100 \mathrm{mg}$ given intramuscularly $1 \frac{1}{2}$ hours prior to surgery. Atropine was omitted.

Anaesthesia was induced intravenously with approximately $100 \mathrm{mg}$ of thiopenthal sodium in 0.5 per cent solution. The patient was breathing spontaneously, oxygen was administered by mask, and the ventilation was augmented with intermittent positive pressure.

To facilitate tracheal intubation, d-tubocurarine chloride $15 \mathrm{mg}$ was injected

'Drs. Brandus, Joffe, and Benoit are from the Department of Anesthesia, and Dr. Wolff is from the Department of Surgery, Beth Israel Medical Center, New York, N.Y. Reprint requests should be sent to Dr. Brandus at Beth Israel Medical Center, Department of Anesthesia, New York, N.Y. 10003.

Canad. Anaesth. Soc. J., vol. 17, no. 3, May 1970 
into the proximal end of the intravenous tube. A few seconds after the injection a marked reddening appeared on the patient's face together with an increased resistance to manually assisted ventilation. An oropharyngeal airway was introduced and positive pressure with oxygen by mask was applied for a few minutes. Inspiratory and expiratory wheezes were audible over both lung fields. As the condition worsened and the patient became cyanotic the anaesthetist, faced with what he considered to be a histamine release by d-tubocurarine, injected $5 \mathrm{ml}$ of a 2 per cent solution of lignocaine $\mathrm{HCl}$, rather rapidly, intravenously. The bronchospasm ended after a few seconds. The blood pressure returned from a systolic of $170 \mathrm{~mm}$ $\mathrm{Hg}$ to the preanaesthetic level, and the trachea was intubated under good conditions of oxygenation and relaxation. A modified radical mastectomy was performed under halothane-nitrous-oxide anaesthesia.

The redness of the face persisted for more than three hours while the patient was in the recovery room, and then gradually subsided. No urticarial reaction was noticed.

\section{Case 2}

S.B., a 56-year-old white male clerk, $166 \mathrm{~cm}$ tall and weighing $66 \mathrm{~kg}$, was admitted to the hospital on November 4, 1968, for an exploratory thoracotomy. A highly suspicious lesion of the right lung had been detected two months previously, but surgery was postponed at that time because of a viral infection. The patient had a history of chronic severe bronchial asthma, chronic bronchitis with emphysema, systemic lupus erythematosus, rheumatic heart disease with mitral stenosis, arteriosclerotic heart disease, and benign prostatic hypertrophy. Long standing medications consisted of glucocorticoids, isoniazides, bronchiodilators, potassium iodide, digitalis preparations, antibiotics, and tranquilizers.

During the 15 preoperative days of hospitalization, while the patient was treated for an intercurrent acute urinary retention, the lungs remained clear on auscultation and the heart pathology was found to be clinically well compensated. Routine laboratory studies were within normal limits, with the exception of a persistent leucocytosis in the vicinity of $20,000 / \mathrm{cmm}$ with a slight shift to the left. Electrocardiogram showed sinus rhythm, rate $100 / \mathrm{min}$, occasional auricular premature contractions, right bundle branch block, and notching of P-wave in lead 3 and AvF. Chest roentgenograms were not remarkable except for the presence of a round infiltrate, $1 \mathrm{~cm}$ in diameter, in the upper lobe of the right lung. Spirometric studies, at the time of admission, were interpreted as indicative of moderate to severe obstructive pulmonary disease with significant emphysema. Throughout the preoperative period, the patient received antibiotics and intermittent positive pressure breathing with nebulization of isoproterenol $\mathrm{HCl}$ and acetylcysteine. The values of the arterial blood gases on the day before surgery were found to be essentially unchanged from those at the time of admission: $\mathrm{Pa}_{\mathrm{O}_{2}} 86 \mathrm{~mm} \mathrm{Hg}$, $\mathrm{Pa}_{\mathrm{CO}_{2}} 33 \mathrm{~mm} \mathrm{Hg}$, haemoglobin oxygen saturation 94 per cent, $\mathrm{pH} 7.42$, and haemoglobin concentration 15.8 gm per cent.

Preanaesthetic medication consisted of dexamethasone (Decadron $\left.{ }^{\circledR}\right) 4 \mathrm{mg}$, meperidine $75 \mathrm{mg}$, and atropine sulphate $0.4 \mathrm{mg}$, administered intramuscularly 90 
minutes prior to the scheduled time for surgery. An intravenous infusion of methyl-prednisolone sodium succinate (Solu-Medrol®), $200 \mathrm{mg}$ in $1000 \mathrm{ml}$ of 5 per cent dextrose in lactated Ringer's solution, was started at the same time.

Before the start of anaesthesia the arterial blood pressure was $140 / 85 \mathrm{~mm} \mathrm{Hg}$, pulse rate $90 / \mathrm{min}$, respiratory rate $15 / \mathrm{min}$, the lungs were clear on auscultation, and the patient was anxious.

Anaesthesia was induced with $300 \mathrm{mg}$ of a 0.5 per cent solution of thiopentone sodium administered intravenously, followed by $100 \mathrm{mg}$ of suxamethonium chloride in 2 per cent concentration. The lungs were ventilated easily with oxygen by mask and the trachea was intubated with a cuffed endotracheal tube. An absolute resistance to inflation of the lungs was immediately apparent. Neither breath sounds nor rhonchi could be heard on auscultation of the chest. The patient was extubated and positive pressure ventilation with oxygen by mask was attempted for a few minutes without benefit. The endotracheal tube was checked for patency and re-intubation performed through a widely opened glottis, positive pressure reapplied, and $4 \mathrm{ml}$ of 1 per cent procaine $\mathrm{HCl}$ were injected intravenously over a 20 -second period. An immediate release from bronchospasm occurred and a satisfactory tidal exchange was obtained at an airway pressure of approximately $25 \mathrm{~mm} \mathrm{Hg}$. Subsequently, hydrocortisone sodium succinate (Solu-Cortef $\circledast$ ) 200 $\mathrm{mg}$ and atropine $0.4 \mathrm{mg}$ were given intravenously, without noticeable effect. The electrocardiogram remained unchanged, the blood pressure at this time was 130 / $80 \mathrm{~mm} \mathrm{Hg}$, and the pulse rate was $110 / \mathrm{min}$. The ensuing period of surgery and anaesthesia (halothane plus nitrous oxide with suxamethonium as relaxant) was uneventful. A right upper lobectomy for a peripheral epidermoid carcinoma was performed without difficulty.

\section{Discussion}

The possibility of histamine-induced bronchospasm in clinical anaesthesia through the use of histamine liberators such as d-tubocurarine was suggested by Comroe and Dripps ${ }^{1}$ and by Paton. ${ }^{2}$ That such a mechanism was responsible for initiating the bronchospasm in our first case is a presumption based on clinical impression, and no other studies were undertaken to substantiate this conclusion.

In the second case, the bronchial spasm can be correlated with a pre-existing condition. Characteristically, in bronchial asthma there are hyperactive tracheobronchial reflexes in response to physical, chemical, or psychogenic-induced stimulation. Experimentally, it was shown by Adriani and Rovenstine ${ }^{3}$ that thiopentone constricts the bronchioles through a direct action and a neurogenic mechanism; also, it is known that it lacks analgesic activity and is a poor suppressor of afferent impulses; it is therefore a drug particularly prone to facilitate vagal reflexes initiated in the respiratory tract or elsewhere in the body. Edwards et al., ${ }^{4}$ investigating ten anaesthetic deaths attributable to bronchospasm, only three of them in patients with a history of asthma, found that the single common factor precipitating the attack appeared to be the stimulation produced by the introduction or the presence of an endotracheal tube in conditions of inadequate reflex suppression. Shnider and Papper, ${ }^{5}$ from the survey of 638 asthmatic patients with a clear 
chest preoperatively, anaesthetized with various agents including thiopentone, reached a similar conclusion.

The ability of procaine to antagonize bronchial muscle contraction induced by thiopentone or cyclopropane was demonstrated experimentally by Adriani and Rovenstine. $^{3}$ Wielding ${ }^{8,7}$ found that no correlation exists between the potency of a drug as a local anaesthetic and its smooth muscle relaxing activity. Comparing cocaine, lignocaine, and procaine, he found cocaine the weakest and procaine the strongest with respect to spasmolytic effectiveness, whereas the anaesthetic potency is in reverse order. Sinha, ${ }^{8}$ performing similar comparative studies on tracheobronchial preparations, also concluded that procaine is a more potent spasmolytic agent than lignocaine, and its antihistaminic activity, investigated by Frommel et $a .^{\theta}$ was found to be markedly greater than that of lignocaine.

The distribution of the local anaesthetics in the tissues, when systemically administered, was investigated by Sung and Truant. ${ }^{10}$ Injecting procaine and lignocaine intramuscularly or intravenously in rats, they found that a selective tissue distribution does occur, the order of decreasing concentrations being kidney, lung, spleen, fat, heart, brain, and liver. An unequal distribution was reported also by Astrom, ${ }^{11}$ but as a function of the drug injected. Comparing prilocaine and lignocaine, Astrom found the concentration of the former in the lung to be double that of the latter.

From the experimental works reviewed, we may infer that $(a)$ local anaesthetic drugs have the property of antagonizing spasm or tension in smooth muscle directly, $(b)$ a preferential distribution of the drug to the lung is a possibility, and (c) the smooth muscle relaxing action is unrelated to the anaesthetic potency of the drug.

If we consider only the most general aspects of the problem, we can regard muscle contraction as the result of four interrelated phenomena: changes in polarization of the cell membrane associated with the development of action potential, followed by spread of the excitation inside the fibre by a coupling mechanism, the release of energy necessary for contraction, and, finally, the activation of the contractile protein. Calcium is essential for electrical and mechanical activity of the muscle cell, two phenomena which, under experimental conditions, can be dissociated. Muscle contraction is associated with an increase in the influx of calcium from the extracellular fluid and a release of calcium ion, bound intracellularly, into the myoplasm. Only when the myoplasmic concentration of calcium ion reaches a critical level is the actomyosin ATP-ase activated and the energy necessary for muscle contraction liberated. Feinstein et al. ${ }^{12-15}$ presented evidence that the relaxing properties of local anaesthetics on smooth muscle are mediated through their ability to interfere with the release of calcium ion from intracellular storage sites as well as with the transmembrane influx and turnover of calcium normally associated with muscle activity.

Clinically, in 1943, Dos Ghali, Bourdin, and Guiot ${ }^{16}$ were the first to publish their results on the use of intravenous injections of procaine in patients suffering from conditions associated with bronchial spasm, such as bronchial asthma and pulmonary embolism. During the subsequent years, as the clinical experience accumulated, no lasting cures were reported, and the method lost its popularity. 
Their recommended effective dose to relax the bronchial muscle, evalued clinically on awake patients, was 50 to $100 \mathrm{mg}$ of a 1 per cent solution of procaine administered at a rate of $10 \mathrm{mg}$ over a 12 to 15 second period.

\section{SUMMARY}

Two cases of severe bronchial spasm in patients under general anaesthesia are presented. In the first case the bronchial spasm, according to our clinical impression, was due to histamine release following a rapid intravenous injection of 15 $\mathrm{mg}$ of d-tubocurarine; $100 \mathrm{mg}$ of lignocaine, administered intravenously, abolished the spasm. In the second case the spasm was induced reflexly by the intubation of the trachea in a patient under thiopentone anaesthesia; $40 \mathrm{mg}$ of procaine, intravenously, ended the attack. The possible mechanisms by which local anaesthetic drugs may induce relaxation of the bronchial muscle are discussed.

\section{RÉSUMté}

Nous avons présenté deux cas de spasme bronchique grave chez des malades sous anesthésie générale. Dans le premier cas, c'est notre diagnostic clinique, le spasme bronchique a été causé par une décharge d'histamine à la suite de l'injection rapide de $15 \mathrm{mg}$ de d-tubocurarine par voie endoveineuse; ce spasme a cédé après l'injection de $100 \mathrm{mg}$ de lignocaïne par voie endoveineuse. Dans le second cas, nous avons attribué le spasme à un réflexe provoqué par l'intubation endotrachéale chez un malade anesthésié au thiopentone; tout est entré dans l'ordre après l'injection de $40 \mathrm{mg}$ de procaine par voie endoveineuse. Nous avons discuté les mécanismes possibles par lesquels les anesthésiques locaux peuvent faire céder le spasme de la musculature bronchique.

\section{REFERENCES}

1. Comroe, J. H. JR. \& Drups, R. D. The Histamine-like Action of Curare and Tubocurarine Injected Intracutaneously and Intra-arterially in man. Anesthesiology. 7: 260 (1946).

2. Paton, W. D. M. The Effects of Muscle Relaxants Other than Muscular Relaxation. Anesthesiology. 20: 453 (1959).

3. Adriani, J. \& Rovenstine, E. A. The Effect of Anesthetic Drugs upon Bronchi and Bronchioles of Excised Lung Tissue. Anesthesiology. 4: 253 (1943).

4. Edwards, G.; Morton, H. J. V.; Pask, E. A.; \& WyLIE, W. D. Death Associated with Anesthesia: A Report of 1000 Cases. Anaesthesia. 11: 194 (1956).

5. Shnider, S. M. \& Papper, E. M. Anesthesia for the Asthmatic Patient. Anesthesiology. 22: 886 (1961).

6. Wielding, S. Contributions to the Pharmacology and Toxioology of Xylocaine. Acta Pharmacol. Toxicol. 8: 117 (1952).

7. Wielding, S. The Specificity and Non-specificity of Substances Having Local Anesthetic Action. Acta Pharmacol. Toxicol. 9: 75 (1953).

8. Sinha, Y. K. Studies on Local Anesthetic Drugs. J. Pharm. Pharmacol. 5: 620 (1953).

9. Frommel, E.; BecK, I. T.; \& Vallette, F. L'Action pharmacodynamique de la xylocaine. Helv. Physiol. Acta. 8: 1 (1950).

10. Sunc, C. \& Truant, A. P. The Physiological Disposition of Lidocaine and Its Comparison in Some Respects with Procaine. J. Pharmacol. Exper. Therap. 112: 432 (1954).

11. Asтrom, A. In Citanest: An International Conference Sponsored by Astra, Santos, Brasil 1964. Ed. S. Wielding, p. 51. Universitetsforlaget: I. Aarhus (1965). 
12. Feinstein, M. B.; Patmat, M.; \& Lee, M. Effect of Local Anesthetics on Excitationcoupling Mechanism. Trans. N.Y. Acad. Sc. 30: 1073 (1968).

13. Feinstein, M. B. \& Paimre, M. Mode of Anticholinergic Action of Local Anesthetics. Nature. 214: 151 (1967).

14. Fensten, M. B. Inhibition of Contraction and Calcium Exchangeability in Rat Uterus by Local Anesthetics. J. Pharmacol. Exper. Therap. 152: 516 (1966).

15. FensstenN, M. B. Inhibition of Caffeine Rigor and Radio-calcium Movements by Local Anesthetics in Frog Sartorius Muscle. J. Gen. Physiol. 47: 151 (1963).

16. Dos Ghali, J.; Bourond, J. S.; \& Gutot, G. La Novocaine par voie veineuse dans les dyspnees. Presse Med. 51: 92 (1943). 